\title{
Síndrome de Lynch. Impacto de la caracterización familiar con base en estudios genéticos en población atendida en IMAT Oncomédica
}

- Jorge Rugeles, Angélica Jayk, Manuel González, Sandra Aruachán, José Lobatón, Estephannia Mora, Alicia Maza IMAT Oncomédica (Montería)

Introducción: el cáncer colorrectal (CCR) es uno de los tumores más frecuentes a nivel mundial, entre el 3\% y 5\% se asocian a síndromes hereditarios, siendo el más frecuente el síndrome de Lynch, un trastorno hereditario autosómico dominante que se caracteriza por mutaciones en la línea germinal en uno o más de los genes de reparación de desapareamiento (MMR) (mutL homolog 1 [MLH1], mutS homolog 2 [MSH2], mutS homolog 6 [MSH6]) y el gen de aumento de segregación posmeiótica 2 [PMS2]. Este síndrome también se caracteriza por un mayor riesgo de inicio temprano de cáncer de endometrio, estómago, ovario, uréter y pelvis renal, intestino delgado, conducto biliar, cerebro y piel. El objetivo del estudio fue identificar las mutaciones genéticas de pacientes con alto riesgo.

Materiales y métodos: se desarrolló un estudio descriptivo, prospectivo, que consistió en realizar la prueba de panel multigénico a 60 pacientes pertenecientes a ocho familias de alto riesgo.

Resultados: el $60 \%$ de los pacientes presentaron mutaciones genéticas, siendo más frecuente la mutación del gen MLH1 con un 59\% versus el MSH2 con un $41 \%$.

Conclusiones: se concluye que la realización del examen genético en pacientes con alto riesgo es de vital importancia para el diagnóstico oportuno de síndrome de Lynch y neoplasias asociadas. 